\title{
Soil Seed Banks of the Exotic Annual Grass Bromus rubens on a Burned Desert Landscape
}

\author{
Benjamin S. Jurand ${ }^{1}$ and Scott R. Abella ${ }^{2}$ \\ Authors are ${ }^{1}$ Graduate Research Assistant and ${ }^{2}$ Associate Research Professor, Department of Environmental and Occupational Health, \\ University of Nevada, Las Vegas, Las Vegas, NV 89154, USA.
}

\begin{abstract}
Red brome (Bromus rubens), an exotic annual grass, can dominate soil seed banks and poses serious threats to mature native plant communities in the Mojave Desert by competing with native species and providing fine fuels that facilitate widespread wildfire. By exploring how seed bank density and composition in burned areas change over time since fire (TSF), we can improve our understanding of how the seed banks are affected by fire. Samples of the 5 -cm-deep soil seed bank were collected from two microsites (under shrubs, in open interspaces) within paired burned and unburned areas on 12 fires ranging from 5-31 yr TSF. Seed bank samples were assayed using the emergence method and seed densities were compared among TSFs, burn status (burned, unburned), and microsites for the species that emerged. Red brome soil seed bank density was spatially variable and TSF rarely predicted abundance. Overall, undershrub seed densities did not differ between burned and unburned areas. However, at some fire sites, seed densities in interspaces were greater in burned than unburned areas. Although native seed densities were low overall, they did not appear to differ according to burn status. Studies have shown that red brome plant and seed bank densities can be greatly reduced immediately after fire. Management efforts that focus on this initial colonization window may be able to take advantage of diminished red brome seed densities to limit its reestablishment while facilitating the establishment of native species. However, this window is brief, as our findings indicate that once reestablished, red brome soil seed densities in burned areas can be similar to those in unburned areas within $5 \mathrm{yr}$.
\end{abstract}

Key Words: desert plant communities, fire chronosequence, microsites, red brome, wildfire

\section{INTRODUCTION}

Annual plants are important components of desert vegetation (Guo et al. 1998), and many species maintain soil seed banks as a bet-hedging strategy against unfavorable years of belowaverage precipitation or drought (Salo 2004). Seed banks represent a collection of dormant seeds in the soil, often comprising multiple generations (Rice and Dyer 2001). With the introduction and proliferation of exotic species, seed banks can be dramatically altered and become dominated by exotic seeds (Cox and Allen 2008). Examining seed banks is a useful tool for understanding such alterations in plant community structure (Espeland et al. 2010). Red brome (Bromus rubens L.), a Mediterranean winter annual grass, is an exotic species in North America and a formidable competitor to native plant species in the deserts of the southwestern United States (Esque et al. 2010). Red brome grows in dense stands, sometimes exceeding 6000 plants $\cdot \mathrm{m}^{-2}$ (Salo 2004), and produces 75 to over 200 seeds per plant (Wu and Jain 1979; Smith et al. 2000). Red brome seeds have less stringent germination requirements than many native annual plants (Salo 2004), requiring as little as $2.5 \mathrm{~cm}$ of rainfall for germination (Beatley 1966). This

Research was funded by a cooperative agreement between the Bureau of Land Management, Las Vegas Field Office, and the University of Nevada, Las Vegas, and by recovered indirect cost funds provided by S. R. Abella.

Correspondence: Benjamin S. Jurand, Dept of Environmental and Occupational Health, University of Nevada, Las Vegas, Las Vegas, NV 89154, USA. Email: jurandb@unlv. nevada.edu

Manuscript received 23 August 2012; manuscript accepted 15 January 2013.

(c) 2013 The Society for Range Management allows red brome to germinate and grow early and use resources otherwise available for native species.

In desert ecosystems, vegetation is spatially distributed such that many annual species-including natives and exotics like red brome-are more abundant under perennial shrub canopies than in the open interspaces between them (Tielbörger and Kadmon 2000). The fertile islands under shrubs can exhibit cooler temperatures and reduced insolation compared to interspaces (Titus et al. 2002), and soils under shrubs can have different properties (Romney et al. 1980; Smith et al. 2000) including greater concentrations of essential soil nutrients such as N, P, K, and organic C (Schlesinger and Pilmanis 1998; Bolling and Walker 2002). Seed banks under shrubs are often denser than in interspaces, as reflected by greater seed inputs from typically higher annual plant densities in shrub island microsites (Guo et al. 1998).

One of the greatest impacts of red brome to invaded desert ecosystems is its ability to spread wildfires. When red brome plants senesce in early summer, dead stalks remain upright and lodged in the soil for up to 3 yr (Brooks 2000). This creates spatially continuous fuel loads that facilitate wildfires, resulting in long-lasting impacts to mature plant communities (Brooks and Matchett 2006; Steers and Allen 2011). Many native plant species in the Mojave Desert are not adapted to widespread or frequent fire (Brooks 2012). Slow-growing and long-lived native plant species are often killed by fire and rarely resprout (Abella 2010). For example, Engel and Abella (2011) reported that blackbrush (Coleogyne ramosissima Torr.) communities are slow to recover following fire and are not likely to reestablish, even within $30 \mathrm{yr}$ of the fire. This reflects ecosystem-wide alterations that result in the conversion of 
mature desert shrub communities to early successional communities dominated by perennial forbs (Abella et al. 2009). Exotic annual species can quickly recolonize burned areas, and once reestablished, contribute additional fuels that further enable fires (D'Antonio and Vitousek 1992). After fire, exotics can greatly outnumber natives or impede their reestablishment by using the limited resources that would otherwise be available to native species (Esque et al. 2010).

In addition to changes aboveground, fires cause numerous impacts that affect seed banks including altered biological, chemical, and physical properties of desert soils (Allen et al. 2011). For example, changes immediately following fire-such as increases in mineral $\mathrm{N}$-can persist over time, especially when exotic species are present (Allen et al. 2011). Fires can also cause soil sterilization, which can influence seed bank longevity by reducing microbial activity and pathogens that damage seeds (Keeley and Fotheringham 2000). Additionally, the removal of aboveground vegetation due to fire can affect the spatial distribution of seeds (Keeley and Fotheringham 2000). High fire temperatures can kill seeds in the soil, destroying both exotic and native seed banks in the process (Abella et al. 2009; Esque et al. 2010). This effect often is greater under shrubs than in interspaces. Patten and Cave (1984) reported that mean maximum fire temperatures at the soil surface under shrubs in Sonoran Desert uplands reached $210^{\circ} \mathrm{C}$, considerably greater than mean maximum fire temperatures at the soil surface in interspaces $\left(60^{\circ} \mathrm{C}\right)$. These temperatures were diminished with increasing soil depths under shrubs, with mean maximum temperatures at a $1-\mathrm{cm}$ depth recorded at $63-90^{\circ} \mathrm{C}$ under shrubs and $61^{\circ} \mathrm{C}$ in interspaces (Patten and Cave 1984). This is reflected in changes to aboveground vegetation after burning, where red brome plant densities are sharply reduced immediately after fire, with greater reductions under shrub canopies (Brooks 2002; Abella et al. 2009). Despite the reduction in red brome abundance in the early years following fire, particularly under shrubs, burned areas often return to or even exceed preburn abundance levels within several years (Brooks 2002). As a result, it is believed fires can help to accelerate dominance of exotic species (Steers and Allen 2011).

Understanding seed bank dynamics in the years following fire is useful for identifying plant community recovery patterns (Esque et al. 2010). By exploring how seed bank density and composition in burned areas have changed over time, we can improve our understanding of how the seed banks of red brome and other species are affected by fire. In this study, we examined soil seed banks from 12 fire sites that burned across a time-since-fire (TSF) gradient from $5 \mathrm{yr}$ to $31 \mathrm{yr}$. Soil seed banks were sampled under shrubs and in interspaces on paired burned and unburned areas at each fire site to address the following research questions: 1) How do red brome seed bank densities change across the TSF gradient?; 2) How do spatial variations in seed bank densities in microsites differ between burned and unburned areas?; 3) Are the seed bank densities of native species affected by fire and if so, is there a relationship between seed densities of red brome and native species?; and 4) How does the overall composition of the seed bank (i.e., exotics relative to natives) compare between burned and unburned areas over the TSF gradient?
We hypothesized that red brome seed densities in burned areas would increase and exceed seed densities in unburned areas over the TSF gradient spanning 5-31 yr. While we generally expected red brome seed densities to be greater under shrubs than in interspaces, we hypothesized that differences between microsites in burned areas would be least in the shortest TSF groups and increase with longer TSF groups as preburn density distribution patterns reestablished. With the potential of red brome to interfere with native species reestablishment after fire, we predicted that native seed densities in burned areas would decrease with greater TSF. By extension, we predicted that red brome (and other exotics) would be more dominant in the seed bank of burned areas with longer TSFs.

\section{METHODS}

\section{Study Area}

Red Rock Canyon National Conservation Area (NCA) is 25 $\mathrm{km}$ west of Las Vegas, Nevada, in the Mojave Desert and has experienced several widespread fires over the past few decades. The Mojave Desert is classified as a hot, arid climate with most precipitation falling in the winter months between October and April in the Las Vegas area. The Red Rock Canyon weather station (lat $36^{\circ} 5^{\prime} \mathrm{N}$, long $115^{\circ} 27^{\prime} \mathrm{W} ; 1152 \mathrm{~m}$ in elevation) has recorded an average precipitation of $300 \mathrm{~mm} \cdot \mathrm{yr}^{-1}$ (1937-2009 records $\left.{ }^{1}\right)$. Above-average winter precipitation occurred in the 2 yr prior to the field sampling, suggesting favorable conditions that facilitate greater red brome seed inputs than in lowprecipitation years (Fig. S1; available online at http://dx.doi. org/10.2111/REM-D-12-00106.s1). Average, maximum, minimum, and extreme temperatures in the $5 \mathrm{yr}$ prior to the beginning of the study were proximate to long-term averages (Fig. S1).

Soil samples were collected from 12 fire sites within and near Red Rock Canyon NCA (Fig. S2; available online at http://dx. doi.org/10.2111/REM-D-12-00106.s2). All plots had confirmed presence of red brome. To minimize the effects of varying postfire recovery pathways in different shrub communities, we focused sampling only on fires in blackbrush communities as defined in Engel and Abella (2011). Unburned sites were dominated by blackbrush while adjacent burned areas often had different species composition. Fires occurred between 1980 and 2006 and were grouped for analysis into similar TSF groups (5-6 yr, 16-18 yr, 23-25 yr, and 28-31 yr TSF). All sites were between $1140 \mathrm{~m}$ and $1700 \mathrm{~m}$ in elevation. Fire sizes ranged from 12 ha to 2550 ha.

\section{Sampling Design}

Collection of seed bank samples occurred in early November 2011, before most winter annual germination occurs in the field (Beatley 1966). No native annuals had yet emerged, but there was some new growth of exotics red brome and redstem filaree (Erodium cicutarium [L.] L'Hér. ex Aiton) seedlings at some of the plots. At each of the 12 fire sites, three plots were sampled in the burned areas and three plots were sampled in paired adjacent unburned areas, for a total of 72 plots.

\footnotetext{
${ }^{1}$ http://www.wrcc.dri.edu
} 
Locations of sample plots within paired burned and unburned polygons were generated using the "random point" generator in the AlaskaPak toolkit, version 2.2, in version 9 of the ArcMap geographic information system (Esri, Redlands, CA). Seed banks were sampled at each plot under shrub canopies and in interspaces.

Although most samples were collected from under blackbrush shrubs, other samples were collected from under burrobush (Ambrosia dumosa [A. Gray] Payne), brittlebush (Encelia virginensis A. Nelson), Nevada jointfir (Ephedra nevadensis $S$. Watson), desert almond (Prunus fasciculata [Torr.] A. Gray), creosote bush (Larrea tridentata [DC.] Coville), and desert globemallow (Sphaeralcea ambigua A. Gray). Three subsamples were collected from three undershrub canopies and were combined into one undershrub sample per plot. Each subsample consisted of $296 \mathrm{~cm}^{3}$ of soil from a $10 \times 10 \mathrm{~cm}, 0-5 \mathrm{~cm}$ deep area (which could include litter on the surface) representing the location of most viable seeds in the seed bank (Guo et al. 1998). Undershrub samples were gathered $10 \mathrm{~cm}$ from the central crown on the north-facing side of the shrub. Soil samples were collected beneath the three largest blackbrush canopies within $10 \mathrm{~m}$ of the plot corner. When blackbrush shrubs were absentas was often the case in burned areas-sampling occurred from under the three largest native perennial plant canopies (of the species noted above) closest to the plot location marker, choosing the dominant species in the immediate area when possible.

Three samples from interspaces were collected at every plot and combined in the same manner. Interspaces were selected by choosing the three closest bare ground areas (which could contain annual plants) at least $1 \mathrm{~m}$ from any shrub canopy within $10 \mathrm{~m}$ of the plot location marker.

\section{Greenhouse Emergence}

Samples were air-dried in the laboratory before being placed in trays $\left(13 \mathrm{~cm} \times 13 \mathrm{~cm} \times 5 \mathrm{~cm}, 845 \mathrm{~cm}^{3}\right)$. Sterile potting soil (Kellogg Garden Products, Carson, CA) and sterile sand (allpurpose sand, supplied by Quikrete, Atlanta, GA) were stirred together, then added to the trays, watered, and left over night. A volume of $296 \mathrm{~cm}^{3}$ from each sample was then placed atop the soil. Six trays with the potting soil and sand mixture were set up without a seed bank sample to serve as controls to test for undesired seed contamination. All trays $(n=150)$ were randomly placed in the greenhouse where they were soaked with water for two consecutive minutes every other day using an automatic misting system. The greenhouse was set up on 14 November 2011 and seeds were allowed to germinate and emerge for a total of $15 \mathrm{wk}$. The average temperature in the greenhouse during the study was $26^{\circ} \mathrm{C}$ with a relative humidity of $35 \%$. Emerged seedlings were identified by species, counted, and removed from the trays. After $2 \mathrm{mo}, 50 \mathrm{~mL}$ of $0.65 \mathrm{M}$ gibberellic acid was applied to each tray in an effort to spur any seeds that might still be dormant (DeFalco et al. 2009). Seedling counts per tray were converted to seeds $\cdot \mathrm{m}^{-2}$.

\section{Data Analysis}

Seed density (seeds $\cdot \mathrm{m}^{-2}$ ) for each species was analyzed in a mixed model analysis of variance (ANOVA) as a hierarchical nested design (Quinn and Keough 2002). The three fixed effects were 1) burn year assigned among sites tested over site nested within burn year, 2) burn status (burned or unburned) assigned within sites and tested over the interaction between burn status and site nested within burn year, and 3) microsite (undershrub and interspace) assigned within plots (tested over the residual). All two- and three-way interactions among the fixed effects were included in the model. Individual fires were included as random effects. The red brome data met model assumptions after square-root transformation. Native species densities were summed and the data were heteroscedastic and had many zeros; thus, significance for these data was assessed by permuting the data 999 times. The exotic species data (total seeds $\cdot \mathrm{m}^{-2}$ ) were square-root transformed, analyzed in the ANOVA, and tested using the permutation process described above. Pairwise contrasts were used to compare significant effects, using normal assumptions or permutations in accordance with the dependent variable. Post-hoc $P$ values were Bonferroni adjusted because we compared burn and microsite effects within each burn year rather than using all possible pairwise comparisons for significant three-way effects. The means and standard errors for total natives were calculated from 10000 bootstrap samples (Efron and Tibshirani 1998). Bootstrap sampling was done in R2.13.0 (R Development Core Team 2011); SASv9.3 (SAS Institute 2002-2008) was used for all other analyses. When the ANOVA revealed a potential relationship between seed densities of red brome and another exotic annual, redstem filaree, in the burned interspaces of one TSF group, we used simple linear regression to examine this relationship further.

Shrub assemblages varied across the 72 plots and were categorized as blackbrush only $(n=44)$, blackbrush mixed with other shrubs $(n=15)$, and other shrubs excluding blackbrush $(n=13)$. We performed a two-way ANOVA on red brome seed densities to test for differences between samples collected under different shrub assemblages and between TSF groups.

\section{RESULTS}

\section{Seed Bank Composition}

Ninety-eight percent of plants that emerged from seed bank samples were exotic species, of which red brome was the dominant species at $92 \%$ of all seeds (Table 1). Red brome was present in samples from $93 \%$ of field plots. The two other annual exotic species identified were Mediterranean grass (Schismus barbatus [L.] Thell.) and redstem filaree. Ten native species were identified in total, the most abundant of which were the annual forbs shaggyfruit pepperweed (Lepidium lasiocarpum Torr. \& A. Gray) and wedgeleaf draba (Draba cuneifolia Torr. \& A. Gray). Mean seed densities for native species were considerably lower than any of the exotic species and emerged from less than a third of greenhouse samples (43 out of 144 greenhouse samples).

\section{Effect of Burn Status and TSF on Seed Densities}

Overall, there was no significant effect of burn status (burned or unburned) on red brome seed bank densities. However, when considering burn status and microsite, red brome seed densities were greater in burned interspaces than unburned 
Table 1. Species that emerged in the greenhouse from 5-cm-deep soil seed bank samples collected in the Mojave Desert.

\begin{tabular}{|c|c|c|c|c|c|}
\hline Scientific name & Common name & Origin & Habit & Family & Mean density \pm SE (seeds $\cdot \mathrm{m}^{-2}$ ) \\
\hline Bromus rubens & Red brome & Exotic & Annual & Poaceae & $5481 \pm 426$ \\
\hline Schismus barbatus & Schismus grass & Exotic & Annual & Poaceae & $275 \pm 102$ \\
\hline Erodium cicutarium & Redstem filaree & Exotic & Annual & Geraniaceae & $105 \pm 27$ \\
\hline Lepidium lasiocarpum & Shaggyfruit pepperweed & Native & Annual & Brassicaceae & $28 \pm 10$ \\
\hline Draba cuneifolia & Wedgeleaf draba & Native & Annual & Brassicaceae & $19 \pm 6$ \\
\hline Encelia spp. & Brittlebrush & Native & Perennial & Asteraceae & $6 \pm 3$ \\
\hline Descurainia pinnata & Tansy mustard & Native & Annual & Brassicaceae & $6 \pm 3$ \\
\hline Plantago ovata & Indianwheat & Native & Annual & Plantaginaceae & $6 \pm 3$ \\
\hline Astragalus spp. & Milkvetch & Native & Perennial & Fabaceae & $5 \pm 2$ \\
\hline Sphaeralcea ambigua & Globemallow & Native & Perennial & Malvaceae & $5 \pm 2$ \\
\hline Thymophylla pentachaeta & Fiveneedle pricklyleaf & Native & Perennial & Asteraceae & $3 \pm 2$ \\
\hline Cryptantha spp. & Cryptantha & Native & Annual & Boraginaceae & $2 \pm 2$ \\
\hline Baileya multiradiata & Desert marigold & Native & Perennial & Asteraceae & $1 \pm 1$ \\
\hline
\end{tabular}

interspaces (Table 2; Fig. 1). Redstem filaree was the only species to have greater seed densities in burned than unburned plots.

Although there were differences in red brome seed densities in some TSF groups, there was no clear pattern over the TSF gradient. The other exotic annual species were only abundant in specific TSF groups. Mediterranean grass had the greatest seed densities in the 5-6 yr TSF group $(P=0.021)$, whereas redstem filaree had the greatest densities in the 16-18 yr TSF group $(P=0.043)$. Native species did not differ across TSF groups.

\section{Seed Densities in Microsites}

Analysis of red brome seed densities collected from under different shrub assemblages revealed no differences between shrub species; all shrub assemblages had similar seed densities. For most TSF groups, there were greater red brome seed densities under shrubs than in interspaces (Fig. 2a). This was true in the youngest fires (5-6 yr TSF) and the oldest fires (23$25 \mathrm{yr}$ TSF and 28-31 yr TSF). The pattern in intermediate years (16-18 yr TSF) was qualitatively reversed and not statistically significant after the Bonferroni correction. The 16-18 yr TSF group had greater red brome seed densities in burned interspaces than unburned interspaces (Fig. 2b). Burn effects were not statistically significant in interspaces of other TSF groups, but there was a marginal trend toward greater seed densities in burned than unburned interspaces (Fig. 2b).

The altered microsite pattern in red brome densities in the 16-18 yr TSF group led us to examine whether there was a relationship between red brome and redstem filaree, which mostly emerged from the same TSF group samples. When comparing seed densities in the 16-18 yr TSF group, there was a positive linear relationship $\left(P=0.006, R^{2}=0.68\right)$ between red brome and redstem filaree in burned interspaces. There were no patterns of red brome seed bank densities under shrubs between burned and unburned areas. Native seed densities were greater under shrubs than in interspaces $(P=0.002)$.

\section{DISCUSSION}

Red brome dominated the seed bank at nearly all the plots sampled in all TSF groups. There was no clear pattern of increased dominance of red brome seeds over native seeds with increasing TSF and therefore the notion that fire can accelerate the dominance of exotic over native species was not supported. Steers and Allen (2011) concluded that when an exotic species has become invasive in an area, it could displace native annuals, regardless of burning. Indeed, even without the occurrence of fire, seed banks can have high densities of exotics in invaded areas (i.e., areas with greater aboveground

Table 2. Analysis of variance (ANOVA) results showing the fixed effects of time since fire (TSF); burned, unburned (burn); and under shrubs, interspaces (microsite) interactions for seed densities of red brome, redstem filaree, Mediterranean grass, and native species on a burned Mojave Desert landscape. $P$ values derived from permuted ANOVA; significant values $(P<0.05)$ denoted in bold.

\begin{tabular}{|c|c|c|c|c|c|c|c|c|}
\hline \multirow[b]{2}{*}{ Variable/Effect ${ }^{1}$} & \multicolumn{2}{|c|}{ Red brome } & \multicolumn{2}{|c|}{ Redstem filaree } & \multicolumn{2}{|c|}{ Mediterranean grass } & \multicolumn{2}{|c|}{ Native species } \\
\hline & $F$ & $P$ & $F$ & $P$ & $F$ & $P$ & $F$ & $P$ \\
\hline $\mathrm{TSF}_{2,8}$ & 0.7 & 0.508 & 2.4 & 0.043 & 0.9 & 0.383 & 0.5 & 0.679 \\
\hline Burn $_{1,3}$ & 10.6 & 0.003 & 14.2 & 0.001 & 0.1 & 0.753 & 0.1 & 0.783 \\
\hline Microsite $_{1,112}$ & 17.4 & 0.001 & 1.2 & 0.305 & 0.0 & 0.879 & 8.3 & 0.002 \\
\hline $\mathrm{TSF} \times$ Burn $_{2,8}$ & 1.4 & 0.219 & 2.4 & 0.090 & 0.5 & 0.689 & 1.1 & 0.329 \\
\hline TSF $\times$ Microsite $_{2,112}$ & 8.5 & 0.001 & 7.1 & 0.002 & 0.6 & 0.662 & 1.3 & 0.309 \\
\hline TSF $\times$ Burn $\times$ Microsite $_{2,112}$ & 0.5 & 0.664 & 0.2 & 0.909 & 3.4 & 0.021 & 1.1 & 0.382 \\
\hline Burn $\times$ Microsite $_{1,112}$ & 6.5 & 0.017 & 0.5 & 0.214 & 1.7 & 0.214 & 1.1 & 0.300 \\
\hline
\end{tabular}

${ }^{1}$ Subscript numbers indicate numerator degrees of freedom, denominator degrees of freedom. 


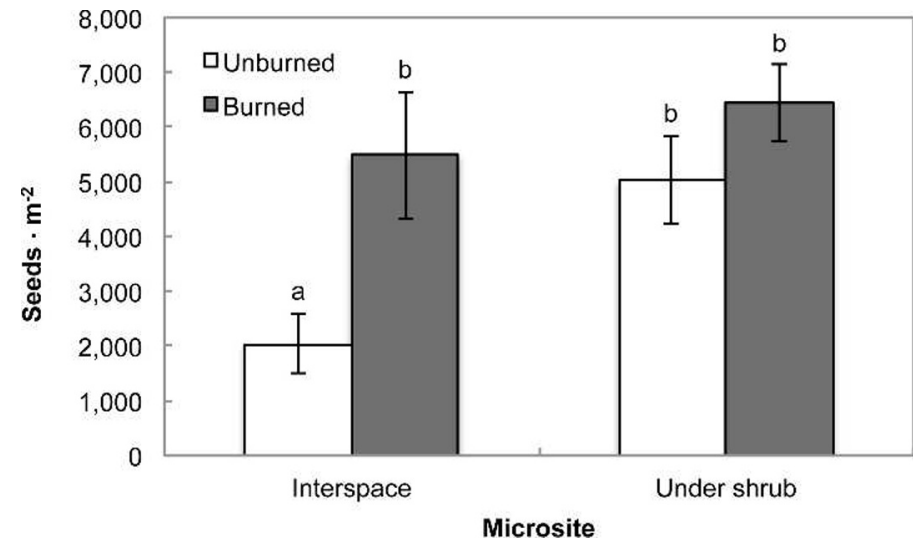

Figure 1. Two-way interactions between red brome seed densities (means $\pm \mathrm{SE}$ ) in microsites and burn conditions from samples of the 5$\mathrm{cm}$-deep soil seed bank in the Mojave Desert. Bars sharing letters do not differ $(P>0.05)$.

exotic species and greater exotic seed bank densities; Schneider and Allen 2012). This may also be the case in our study, as red brome was clearly dominant in samples from nearly all plots $(92 \%)$. However, because data for native seeds were relatively depauperate, broad conclusions regarding natives are difficult to make, and a comparison of native seed densities in areas where red brome was present to where it was absent was not feasible. In any case, we cannot conclude that the occurrence of fire itself alters conditions in such a way to favor increased red brome seed densities, at least overall, and there does not appear to be a clear successional pattern that changes between $5 \mathrm{yr}$ and 31 yr TSF.

\section{Effect of Burn Status and TSF on Seed Densities}

Generally, red brome seed densities did not differ greatly between burned and unburned areas and did not increase with longer TSFs. Even the youngest fire sites sampled (burned $5 \mathrm{yr}$ prior) exhibited red brome seed bank density similar to their unburned counterparts. It is thought that despite diminished populations immediately after fire, red brome can rebound and exceed unburned densities (Brooks 2002). However, this effect was variable at the site level; some sites had greater or equal seed densities in burned compared to unburned areas, while others had lower densities. Further research should be conducted on changes in the seed bank immediately following fires to understand how quickly the seed bank becomes saturated with red brome seeds.

How quickly and easily red brome seed banks regenerate in burned areas may be influenced by the altered ecological structure of each burned area as well as the particular characteristics of each fire. Heat from fires can kill seeds in the soil, particularly under shrubs where mean maximum fire temperatures can be greater than in interspaces (Patten and Cave 1984). Fire temperatures can also vary according to soil depth. For example, in a summer Mojave Desert fire, Brooks (2002) observed temperatures under shrubs that varied from $170^{\circ} \mathrm{C}$ at the surface to $110^{\circ} \mathrm{C}$ at a $2-\mathrm{cm}$ depth. Additionally, experimental heating of seeds has also resulted in reduced seedling emergence of red brome when seeds were exposed to $100^{\circ} \mathrm{C}$ temperatures (Abella et al. 2009). We can therefore

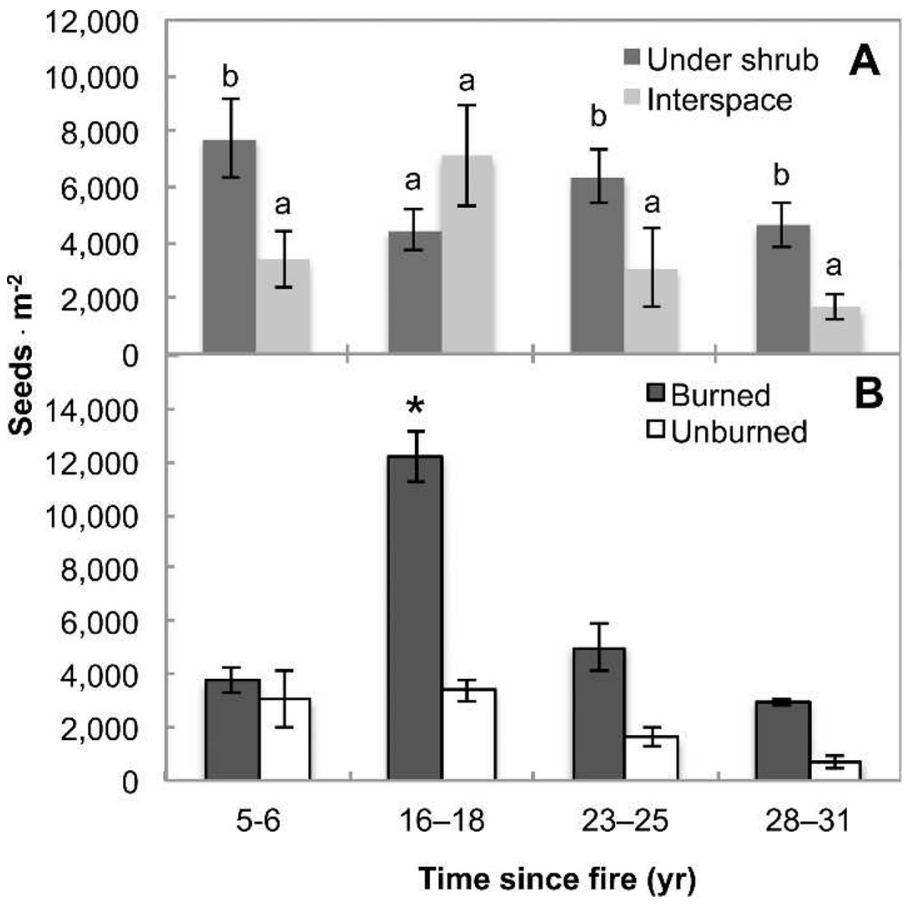

Figure 2. A, Comparison of red brome seed densities (means $\pm \mathrm{SE}$ ) in microsites and time-since-fire (TSF) groups including both burned and unburned areas; bars sharing letters do not differ $(P>0.05)$. B, Red brome seed densities (means $\pm \mathrm{SE}$ ) in interspace microsites on burned and unburned plots and TSF groups; asterisks indicate significant differences $(P<0.05)$.

expect that in a postfire environment, the seed bank complement is a function of which seeds-if any-survive the fire, as well as the postfire inputs from seed production and retention in the soil. Seed banks of annuals are ephemeral and variable over time, dependent on annual precipitation and environmental conditions during the current and prior years (Venable 1989). With no overall effect of burning or TSF on red brome seed densities observed in this study, reestablished red brome populations following fires may be more affected by climate variations than by any changes to the soil or surrounding environment that are the result of fire.

\section{Seed Densities in Microsites}

In unburned areas and in most TSF groups, red brome seed densities were lower in interspaces than under shrubs. This concurs with our expectations that undershrub microsites have greater annual plant densities and greater seed densities than interspaces (Guo et al. 1998). The occurrence of fire did not appear to influence red brome seed densities under shrubs, although burning did appear to have some impact on seed densities in burned interspaces. This was only observed at certain sites, however, and is likely a result of individual variations among sites in vegetation conditions or soil characteristics. A closer examination at the sites with greater seed densities in burned interspaces compared to unburned interspaces revealed the greatest densities of exotic redstem filaree as well. Numerous studies have confirmed the propensity for redstem filaree to rapidly increase in burned areas after fire (Abella 2010; Brooks and Chambers 2011; Steers and Allen 
2011). Indeed, in this study, redstem filaree was the only species to show a significant difference between burned and unburned areas.

Direct comparisons between burned and unburned areas under shrubs must be made cautiously owing to differences in aboveground vegetation between burned and unburned areas. Many of the shrubs in burned areas under which we sampled were early successional species, such as desert globemallow, and could not be paired with samples from under the same species in unburned areas because of differences in postfire species composition. Seed densities under shrubs were fairly similar overall, however, and shrub assemblages (i.e., blackbrush only, mixed blackbrush, or no blackbrush) did not appear to have an effect on seed densities. Ultimately, seed densities in undershrub microsites were less variable between burned and unburned areas than was the case in interspaces. In fact, the early-successional perennial shrubs in burned areas had similar undershrub red brome seed densities to the latesuccessional fertile islands in unburned areas. This suggests that shrub assemblages (at least, those sampled in this study) and successional types (i.e., early- or late-successional) do not greatly influence undershrub red brome seed densities.

\section{IMPLICATIONS}

Red brome clearly has the ability to dominate seed banks. However, there were no discernible patterns of changing red brome seed densities over the TSF gradient and only a variable impact due to burning. Differences between burned and unburned areas were greatest in interspaces, with greater red brome seed densities in burned interspaces. This is likely due to site variation, but may be related to other exotic annual species that also increased in burned interspaces, such as redstem filaree. Although native seed densities were low overall, they did not appear to be affected by burning.

Studies have shown that red brome plant and seed bank density can be greatly reduced immediately after fire. This period of reduced red brome presence after fire represents a potential window of opportunity for managers to implement active revegetation efforts that limit the reestablishment of red brome while facilitating the establishment of native species (Brooks 2002). This may include such activities as seeding native species (Abella et al. 2009) or the application of preemergent herbicide (Kyser et al. 2007). Since burn status had only a variable effect on overall red brome seed densities (even in the shortest TSF group), this window is likely to be brief. A closer examination of changes in seed bank density in the critical first years following fire is warranted because, as indicated by the sites in this study, once reestablished, red brome seed densities in burned areas can be virtually indistinguishable from unburned areas in as little as $5 \mathrm{yr}$ after fire.

\section{ACKNOWLEDGMENTS}

We thank the Bureau of Land Management, Las Vegas Field office (in particular Christina Lund), for facilitating this study; Cheryl Vanier for assistance with the statistical analyses; Cayenne Engel for assistance with sampling design and plant identification (with additional help from Joslyn Curtis); and Stanley Smith, Cayenne Engel, Randy Stollar, the Associate
Editor, and two anonymous reviewers for providing comments to improve the quality of this manuscript.

\section{LITERATURE CITED}

AвeLLA, S. R. 2010. Disturbance and plant succession in the Mojave and Sonoran deserts of the American Southwest. International Journal of Environmental Research and Public Health 7:1248-1284.

Abella, S. R., E. C. Engel, C. L. Lund, and J. E. Spencer. 2009. Early post-fire plant establishment on a Mojave Desert burn. Madroño 56:137-148.

Allen, E. B., R. J. Steers, and S. J. Dickens. 2011. Impacts of fire and invasive species on desert soil ecology. Rangeland Ecology \& Management 64:450-462.

Beatley, J. C. 1966. Ecological status of introduced brome grasses (Bromus spp.) in desert vegetation of southern Nevada. Ecology 47:548-554.

Bolling, J. D., AND L. R. Walker. 2002. Fertile island development around perennial shrubs across a Mojave Desert chronosequence. Western North American Naturalist 62:88-100.

Brooks, M. L. 2000. Bromus madritensis ssp. rubens (L.) Husnot. In: C. C. Bossard, J. M. Randall, and M. C. Hoshovsky [EDS.]. Invasive plants of California's wildlands. Berkley and Los Angeles, CA, USA: University of California Press. $p$. 360.

Brooks, M. L. 2002. Peak fire temperature and effects on annual plants in the Mojave Desert. Ecological Applications 12:1088-1102.

Brooks, M. L. 2012. Effects of high fire frequency in creosote bush scrub vegetation of the Mojave Desert. International Journal of Wildland Fire 21:61-68.

Brooks, M. L., AND J. C. Chambers. 2011. Resistance to invasion and resilience to fire in desert shrublands of North America. Rangeland Ecology \& Management 64:431-438.

Brooks, M. L., AND J. MATCHEtT. 2006. Spatial and temporal patterns of wildfires in the Mojave Desert, 1980-2004. Journal of Arid Environments 67:148-164.

Cox, R., and E. Allen. 2008. Composition of soil seed banks in southern California coastal sage scrub and adjacent exotic grassland. Plant Ecology 198:37-46.

D'Antonio, C. M., AND P. M. Vitousek. 1992. Biological invasions by exotic grasses, the grass/fire cycle, and global change. Annual Review of Ecology and Systematics 23:63-87.

DeFalco, L. A., T. C. Esque, J. M. Kane, and M. B. Nicklas. 2009. Seed banks in a degraded desert shrubland: influence of soil surface condition and harvester ant activity on seed abundance. Journal of Arid Environments 73:885-893.

EFron, B., AND R. J. TibShiRANI. 1998. An introduction to the bootstrap. Boca Raton, FL, USA: CRC Press. $456 p$.

Engel, E. C., and S. R. Abella. 2011. Vegetation recovery in a desert landscape after wildfires: influences of community type, time since fire and contingency effects. Journal of Applied Ecology 48:1401-1410.

Espeland, E. K., L. B. Perkins, and E. A. Leger. 2010. Comparison of seed bank estimation techniques using six weed species in two soil types. Rangeland Ecology \& Management 63:243-247.

Esque, T. C., J. A. Young, and C. R. Tracy. 2010. Short-term effects of experimental fires on a Mojave Desert seed bank. Journal of Arid Environments 74:13021308.

Guo, Q., P. W. Rundel, AND D. W. Goodall. 1998. Horizontal and vertical distribution of desert seed banks: patterns, causes, and implications. Journal of Arid Environments 38:465-478.

KeEley, J. E., And C. J. Fotheringham. 2000. Role of fire in regeneration from seed. In: M. Fenner [ED.]. Seeds: the ecology of regeneration in plant communities. New York, NY, USA: CABI Publishing. p. 311-330.

Kyser, G. B., J. M. DiTomaso, M. P. Doran, S. B. Orloff, R. G. Wilson, D. L. Lancaster, D. F. LILE, And M. L. PoRath. 2007. Control of medusahead (Taeniatherum caputmedusae) and other annual grasses with imazapic. Weed Technology 21:66-75.

Patten, D. T., and G. H. Cave. 1984. Fire temperatures and physical characteristics of a controlled burn in the upper Sonoran Desert. Journal of Rangeland Management 37:277-280.

QuinN, G. P., And M. J. Keough. 2002. Experimental design and data analysis for biologists. New York, NY, USA: Cambridge University Press. 537 p. 
R Development Core Team. 2011. R: a language and environment for statistical computing. Vienna, Austria: R Foundation for Statistical Computing.

RicE, K. J., AND A. R. Dyer. 2001. Seed aging, delayed germination and reduced competitive ability in Bromus tectorum. Plant Ecology 155:237-243.

Romney, E. M., A. Wallace, H. Kaaz, and V. Hale. 1980. The role of shrubs on the redistribution of mineral nutrients in soil in the Mojave Desert. Great Basin Naturalist Memoirs 4:124-133.

SaLo, L. F. 2004. Population dynamics of red brome (Bromus madritensis subsp. rubens): times for concern, opportunities for management. Journal of Arid Environments 57:291-296.

SAS InStituTe [COMPUTER PROGRAM]. 2002-2008. SAS Software version 9.3. Cary, NC, USA: SAS Institute.

Schlesinger, W. H., and A. M. Pilmanis. 1998. Plant-soil interactions in deserts. Biogeochemistry 42:169-187.

Schneider, H. E., And E. A. Allen. 2012. Effects of elevated nitrogen and exotic plant invasion on soil seed bank composition in Joshua Tree National Park. Plant Ecology 21:1277-1287.
Smith, S. D., T. E. Huxman, S. F. Zitzer, T. N. Charlet, D. C. Housman, J. C. Coleman, L. K. Fenstermaker, J. R. Seemann, and R. S. Nowak. 2000. Elevated $\mathrm{CO}_{2}$ increases productivity and invasive species success in an arid ecosystem. Nature 408:7982.

Steers, R. J., and E. B. Allen. 2011. Native annual plant response to fire: an examination of invaded, 3 to 29 year old burned creosote bush scrub from the western Colorado Desert. Natural Resources and Environmental Issues 17:20.

Tielbörger, K., AND R. Kadmon. 2000. Indirect effects in a desert plant community: is competition among annuals more intense under shrub canopies? Plant Ecology 150:53-63.

Titus, J. H., R. S. Nowak, and S. D. Smith. 2002. Soil resource heterogeneity in the Mojave Desert. Journal of Arid Environments 52:269-292.

Venable, D. L. 1989. Modeling the evolutionary ecology of seed banks. Ecology of Soil Seed Banks 67:60-384.

Wu, K. K., AND Jain, S. K. 1979. Population regulation in Bromus rubens and B. mollis: life cycle components and competition. Oecologia 39:337-357. 